\title{
Investigation of SkyCabs Monorail System in Urban Regions
}

\author{
Avishai (Avi) Ceder, Mitchell Roberts, Ryan Schermbrucker \\ Faculty of Engineering, Department of Civil and Environmental Engineering, University of Auckland, \\ Auckland, New Zealand \\ Email: a.ceder@auckland.ac.nz
}

Received December 2013

\section{Abstract}

The increased popularity of the private vehicle and the low budgets available to public-transport (PT) planners has meant that PT patronage has decreased significantly from what it once was. This has led to congestion and pollution problems in many cities around the world. It is thus apparent that new, high quality and sustainable PT system is needed to open the opportunity to attract more people to use PT. This work describes such a system called SkyCabs. The SkyCabs concept is comprised of many, lightweight, driverless cabs running two ways on a single elevated monobeam. With each cab seating up to eight people, the aim is to create a feeling of personal travel, and in doing so increase the level of patronage on PT services. The SkyCabs system is investigated based on the following three criteria; a comparative analysis which involves researching and comparing system characteristics, a computer simulation analysing operational feasibility and an economic analysis which involves calculating and comparing the benefit-cost ratios for each mode analysed. A background section has been included to provide information on existing PT modes which have been compared to SkyCabs throughout this work. The SkyCabs concept has been deemed feasible within an urban context such as the North Shore of Auckland, New Zealand. This finding is based on a comparison with other options investigated and it is due to SkyCabs favourable characteristics, the high level of service offered and the low cost of implementation relative to return benefits.

\section{Keywords}

Monorail; Public Transport; SkyCabs

\section{Introduction and Research Objective}

Over the last 50 years public-transport (PT) patronage has steadily declined largely due to an increase in private motorcar popularity (Lee, 2011). This has resulted in widespread congestion, costing billions in wasted time, fuel and accidents every year (Chapman et al., 2011). In addition, the world's population is growing rapidly and is expected to increase to approximately 9.3 billion by 2050 (Haub, 2008). This growth is placing an ever increasing amount of pressure on both public and private transportation infrastructure across the globe. Traditional forms of PT, such as bus and rail, have been ineffective in attracting the private motorist and coping with the in- 
crease in population (Grimes, 2007). This has especially been the case in cities with low population densities (Coleman, 2010). New, innovative forms of PT are therefore required to successfully draw people from their cars in order to reduce congestion and cater for the ever increasing transport demands.

This research specifically looks at one such system labeled as SkyCabs, designed in New Zealand (Chapman, 2006). SkyCabs comprises of lightweight, 8-seater, automated cabs which travel up to $80 \mathrm{~km} / \mathrm{hr}$ on a two-way, elevated moonbeam (Chapman et al., 2011). The system runs on an on-demand basis with high frequencies resulting in fast, pollution free, unimpeded travel. Artistic impressions and schematics of SkyCabs are illustrated in Figure 1 and Figure 2.

The objective of this research is to evaluate the feasibility of incorporating a SkyCabs system into any low density urban area. This was completed by evaluating a hypothetical SkyCab network, located on the North Shore of Auckland, New Zealand. The evaluation involved undertaking an operational, comparative and economic analysis in order to compare the results to other modes of traditional and modern transport systems.

\section{Literature Review}

\subsection{Public Transport around the World}

For many cities around the world, transportation infrastructure has become a significant issue due to concerns about traffic congestion and pollution. Traditional solutions involved building new roads and highways in order to cater for the ever increasing population. Laird et al. (2001) suggests that a more balanced approach than traditional solutions is required, and that provision for mass transit functions should be in the form of some type of fixed rail system.

Rail has been suggested because it offers a dedicated guideway which will generally outperform buses and vehicles in terms of the level of service it is able to provide during busy periods, as can be seen in the comparison between the Sydney and Atlanta Olympic games transport arrangements by Laird et al. (2001). Sydney had a fairly comprehensive rail network that could comfortably handle the 50,000+ people per hour while Atlanta attempted and failed to move all passengers with buses and cars. However, in saying this, any system that gets passengers off the road network and onto a dedicated PT system will help to improve travel times, level of service and congestion related issues.

Systems such as the Austrans, developed by Arthur Bishop, has proven that smaller rail based systems have the ability to operate at higher speeds than buses and conventional personal rapid transit (PRT) systems while

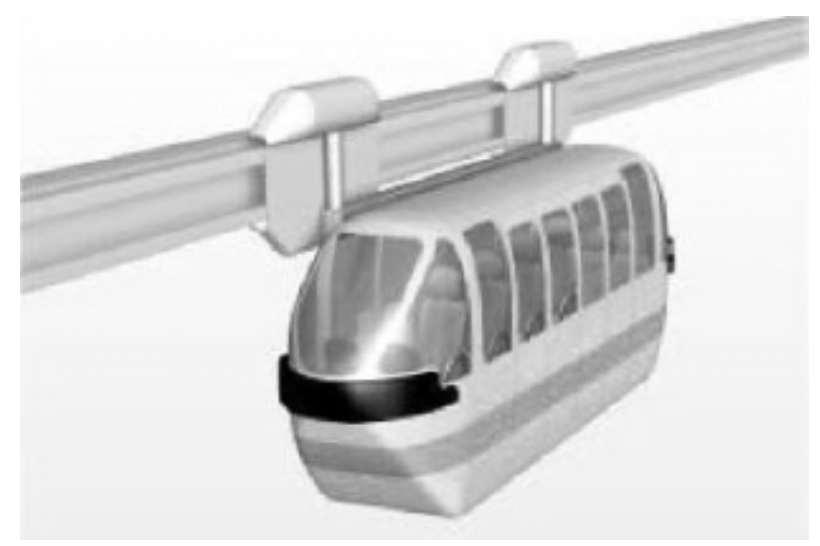

Figure 1. Artists impression of SkyCabs (Chapman, 2006).
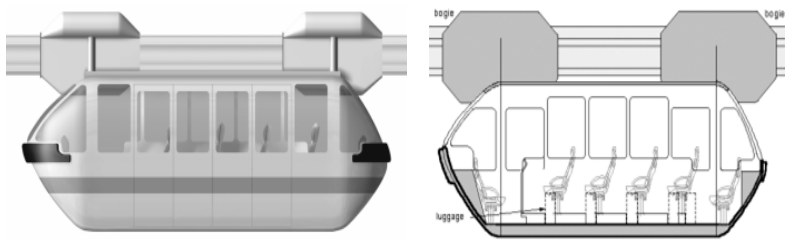

Figure 2. Elevation view of SkyCabs (Chapman, 2006). 
maintaining a much smaller cornering radii than conventional monorails (Davidson, 2004). SkyCabs has a further potential benefit over Austrans in that it runs on a single elevated monobeam allowing it to traverse through even smaller transport corridors.

\subsection{Public Transport in Auckland}

As the city has expanded, Auckland has formed an agglomeration of a number of satellite centers of business and industry (Grimes, 2007). This has made it difficult for transportation planners to provide an easily accessible PT network in a city where an already small population is travelling to/from a number of different destinations during peak hours. However, these agglomerations are vital to the economic growth of the city, allowing business to expand and develop in a way not possible without this urban spatial structure (Quigley, 1998).

Conventional PT solutions such as buses and trains do not deal with this population model very well as they require a relatively high number of people to be headed to/from the same destination or along the same route in order to provide a level of service high enough to attract passengers from private vehicles to public transportation.

Additions to the Auckland light rail network are being considered for the future development of Auckland city (Auckland Regional Transport, 2010). This strategy fits well with the ideas put forward by Laird et al. (2001) as well as working to achieve one of the goals stated in the Auckland Transport Plan to reduce the amount of vehicles on the road.

Light rail is a well proven PT option (Dawson, 2003) that lends itself to political and public approval, however, the cost and space requirements are high when compared to smaller PRT type systems as well as the SkyCabs system. The PRT and SkyCabs, although not as proven as light rail, offer enough significant benefits to warrant serious consideration and investigation in order to determine whether a system such as SkyCabs would work within the Auckland context (Dawson, 2003).

The topography of the Auckland region means that often there is limited land available for transport corridors (Harris, 2005; Bachels et al., 1999). Examples of this constriction include the state highway 16 causeway and the Auckland Harbour Bridge. The need for a PT system that can not only remove cars from these pinch points, but also require minimal amounts of land to implement is clear. Within the central business center (CBD) itself the land is hilly, with many significant grade changes and tight street corners, which is a problem for conventional city monorail systems such as the Bombardier built track used in the Jacksonville downtown connector monorail (Monorails.org, 2012). These conventional systems also require large stations which is expensive and problematic to fit into the already crowded Auckland CBD area.

\subsection{Potential Solutions}

\subsubsection{Personal Rapid Transit (PRT)}

One transport option that has been considered as early as 1965 (Sulkin, 1999) is a Personal Rapid Transit Network. This type of system has been successfully implemented in a number of smaller networks, however Sulkin (1999) notes that there are still some substantial technical obstacles to consider when developing this system for a city center sized network. A number of these obstacles (such as the need to meet a larger more varied demand) have been addressed by systems like Austrans and SkyCabs by increasing the capacity of the cabs from the more conventional 4-6 to 8 or 9 (16 in the case of standing passengers on SkyCabs) (Chapman et al., 2011).

One reason why it is difficult to attract people to public transport is due to the ever increasing popularity of the private motor vehicle (Jakob et al., 2006, Bachels et al., 1999, Laird et al., 2001). This is particularly relevant in the Auckland region where car ownership has increased dramatically and public transportation patronage has plummeted (Jakob et al., 2006). It has been suggested by Wright and Egan (2000) that public transport providers need to de-market the car in order to get more people onto public transport. This can be difficult to do as the convenience, flexibility and value of a private vehicle is very difficult for public transport to compete against (Lee, 2011).

A new and innovative transportation network such as PRT and the PRT-like SkyCab system which showcases the latest technology and provides panoramic views during trips (Chapman et al., 2011) is in a position to encourage this de-marketing by focusing attention away from the car by offering something more than what is currently available. The environmentally friendly nature of the SkyCabs system is also a favourable comparison to that of the motorcar, which is an important factor in today's society. A new network that works in harmony 
with existing services such as the SkyCabs concept would not only increase the level of service in all areas, but it would have the advantage of increasing interest in the public transport network and enticing more people out of their cars and off the roads (Chapman et al., 2011).

\subsubsection{Group Rapid Transit (GRT)}

GRT is a form of collective public transport using automated electric "cyberbuses" to provide scheduled and/or on demand service for larger groups of people (Niches, 2010). These cyberbuses are designed to transport larger groups of people than PRT type systems (typically around 20-100 passengers (Muller, 2007)). Niches (2010) highlights some of the advantages of implementing a GRT system, these include its low operating costs as drivers are often not required, both scheduled and on-demand services are possible depending on the need and pollution reductions as vehicles are automated, electric and quiet.

Muller (2007) compares the attributes of PRT to that of GRT type systems. He states that GRT systems have a larger capacity, going on to say that one GRT guideway could have more than twice the capacity of one PRT guideway. However, this is offset by the costs which are usually far larger for GRT systems due to the size of cabs and stations required. Kerr et al. (2005) states that PRT column loads are approximately $10 \%-12 \%$ of typical GRT column loads and Muller (2007) has found that PRT stations are typically $76 \%$ of the size of GRT stations. As GRT stations are larger, they are more difficult to build in dense city environments.

PRT passengers have the privacy and comfort of being seated in a cab without having to share rides with strangers. The travel speeds of PRT systems are relatively slow compared to that of GRT, however the total trip times are likely to be faster than GRT trip times due to the reduced waiting times and the elimination of intermediate stops. In addition to this, PRT type systems are likely to have more stations resulting in reduced walking distances and times (Muller, 2007).

\subsubsection{Conventional Bus}

Buses have the advantage of flexibility in that they can adapt to a changing environment quickly and without much financial investment. They are also a proven technology which allows precise costing of any future networks. However, they can be expensive to run due to the need for a driver who is only fully utilised during two peak periods of the day (Lee, 2011) and ever increasing fuel costs. In addition to this, buses are generally subject to the same congestion and environmental impacts as cars. This is not the case on dedicated bus lanes and guideways such as the Northern busway on Auckland's North Shore, however, even these routes experience a reduced level of service at points where they merge back into the main traffic flow.

Bus capacity is another issue that is a cause for concern, as with the drivers the full capacity of the bus is often only utilised during the two peak periods of the day. Meaning that the average daily load factor can be as low as one third of the capacity of the vehicle (Lee, 2011). However, this is not to say that buses are not a useful form of public transport as they tend to work well for a specific kind of passenger and cannot necessarily meet today's diverse passenger needs. Chapman et al. (2011) suggests that a multi-modal transport network using a SkyCab system as a link to and between bus and train services could greatly increase the level of service offered to the Auckland public. This suggestion is based on the predicted ability of the SkyCab system to handle a very diverse range of passenger needs.

\subsubsection{Conventional Rail}

Light rail is a popular choice among transport planners as it generally attracts passengers away from the road network. It is also considered an environmentally friendly option (Chapman, 2006) which is often a deciding factor in today's political climate. The electrification of the Auckland rail network and planned expansion (Auckland Regional Transport, 2010) is evidence of the appeal of an environmentally friendly system.

One of the major issues faced with rail in an urban or sub urban environment is the noise and vibration caused by the large carriages (Chapman, 2006). This has the potential to not only annoy, but cause some serious health affects within a community (Willmott, 1998; Niches, 2010; Muller, 2007) and should be given serious consideration in any transport plan involving a rail network.

Due to the at grade nature of most light rail networks, safety at intersections between rail and other forms of transport is a major concern and many studies (Kerr et al., 2005; Hensher, 2007) have focused on this issue.

The SkyCabs system addresses many of the concerns about light rail. Firstly it runs on an elevated guide way above the current transport corridor, this eliminates the risk of collisions between different modes of transport at 
intersections. And while certain sectors of the decision making community are hesitant about SkyCabs due to its unproven nature (Dawson, 2003), safety records for driverless transport systems like SkyCabs have been reported as even better than many manual systems currently in operation (Thompson, 2009). SkyCabs also employs hard wearing rubber wheels and an electric motor to allow whisper quiet operation (Chapman et al., 2011).

\section{Methodology}

The research methodology is shown in Figure 3. The initial stages of the project involved obtaining origin-destination (OD) and other characteristic data; in the case of this work the OD data sets were obtained from the Auckland Transport (AT) government agency. From here comparative, operational and economic analyses were undertaken before drawing conclusions from the results.

\subsection{Comparative Analysis Methodology}

The comparative analysis involved obtaining information from SkyCabs International Ltd and other literature on the following expected SkyCabs system characteristics:

- Maximum theoretical capacity

- Average travel speed

- Energy consumption

- Operation and Maintenance (O\&M) costs

- Average capital costs

Information on the same system characteristics were then determined by carrying out research for each of the following traditional and modern modes of transport:

- Bus

- Light rail

- Private vehicles

- Personal Rapid Transit (PRT)

- Group Rapid Transit (GRT)

As a basis for comparison, all the researched monetary values were converted to 2012 dollars by applying an inflation factor. They were then converted to New Zealand dollars (NZD) using the following exchange rates valid as of July 2012:

$1 \mathrm{NZD}=0.79$ United States dollars

$1 \mathrm{NZD}=0.50$ British pounds

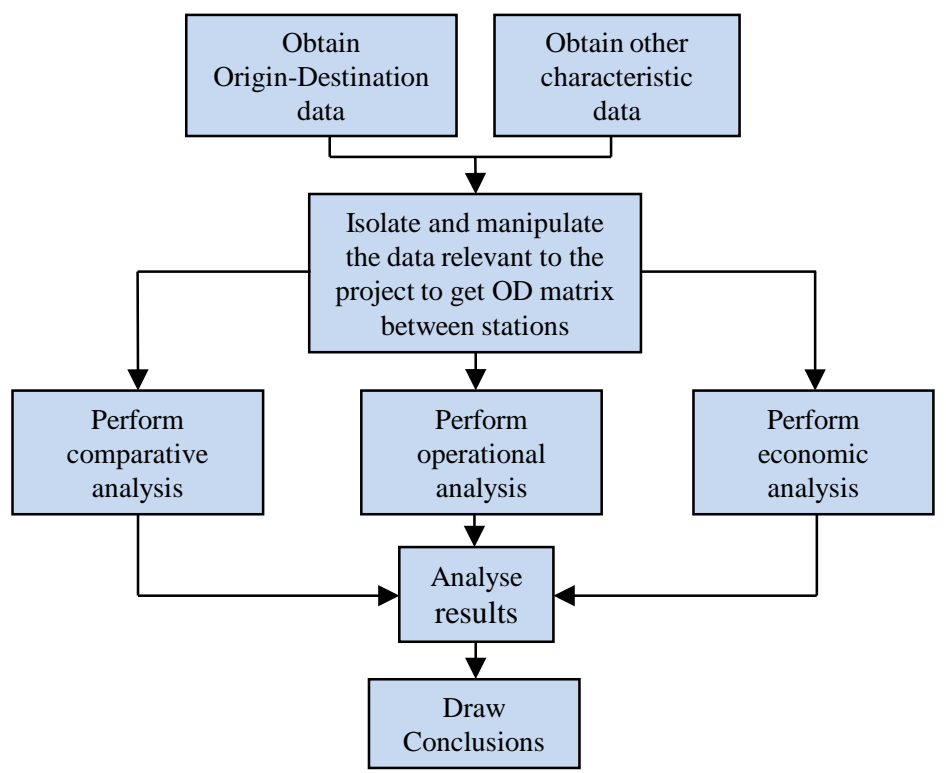

Figure 3. Project methodology. 
$1 \mathrm{NZD}=0.78$ Australian dollars

$1 \mathrm{NZD}=0.63$ Euro

The results of the comparative analysis were used to compare system characteristics between SkyCabs and other forms of transport in order to help determine the overall feasibility of the SkyCabs system.

\subsection{Operational Analysis Methodology}

\subsubsection{Data Processing}

The data received from AT was in the form of an OD matrix for PT person trips and private vehicle cars trips. The private vehicle trips were converted to person trips by multiplying the number of trips by 1.3 (Fabian, 2004; Åberg, 1988). Each OD matrix consisted of over 500 circular zones defined by coordinate centers and a zone area.

The first step was to plot each zone centre on a map and isolate the zones relevant to the project. Google Fusion Tables were used to create a KML file of the location of each zone and its corresponding zone number, this KML file was loaded into Google Earth to create a map that had each zone plotted and labelled.

Next the proposed network and its stations were drawn onto the map and the zone trips were converted to station trips based on the size and location of the zone relative to the station. The generalised method used for this conversion is shown in Figure 4.

The area of overlap between the 15 min walking distance to the station and the zone area shown in Figure 4 gives an indication of the percentage of zone trips that are likely to become station trips. Some zone trips were recconciled from further out than the fifteen minute walking distance due to the likelyhood of longer trips, such as those into the CBD originating further from the station.

The case study of this work is the proposed SkyCab network connecting the North Shore of Auckland to the $\mathrm{CBD}$ as is shown in Figure 5. The method illustrated in Figure $\mathbf{4}$ was used to determine the number of trips within a ten minute walking distance of a dedicated PT station for both SkyCabs and the Northern Busway. These ten minute walking distances are illustrated in the case study in Figure 5.

The transformation shown in Figure 5 produced two station to station matrices that represented the full network travel for both public transport and private travel. At this point a decision on the likely mode switch percentages was required in order to determine the final input for the model.

\subsubsection{Mode Switch Predictions}

\section{1) Mode switch from $P T$}

The Multinomial Logit (MNL) Model (Tassi et al., 2010) presented in Equation (1) was used to calculate transfer percentages from existing PT services to SkyCabs.

$$
P_{m}=\frac{e^{u(m)}}{\sum_{i=1}^{n} e^{u(i)}}
$$

where, $P_{m}$ is the probability of a PT user choosing mode $\mathrm{m}$, given the utility factor, u of each mode.

The utility factor, $\mathrm{u}$ is based on indicators such as cost and trip time. In the case study, the values adopted for the purposes of this research are values obtained during and after the implementation of a fast rail system in Hong Kong that produced a similar level of service to the level predicted based on SkyCabs specifications, and

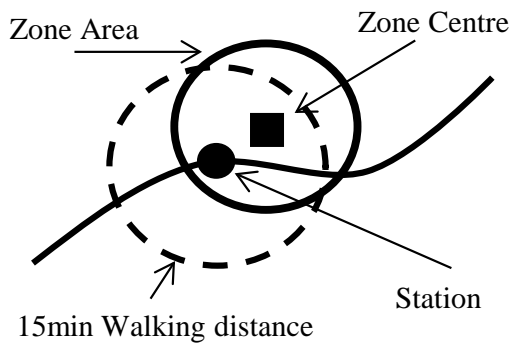

Figure 4. Method for reconciling zone trips to stations. 


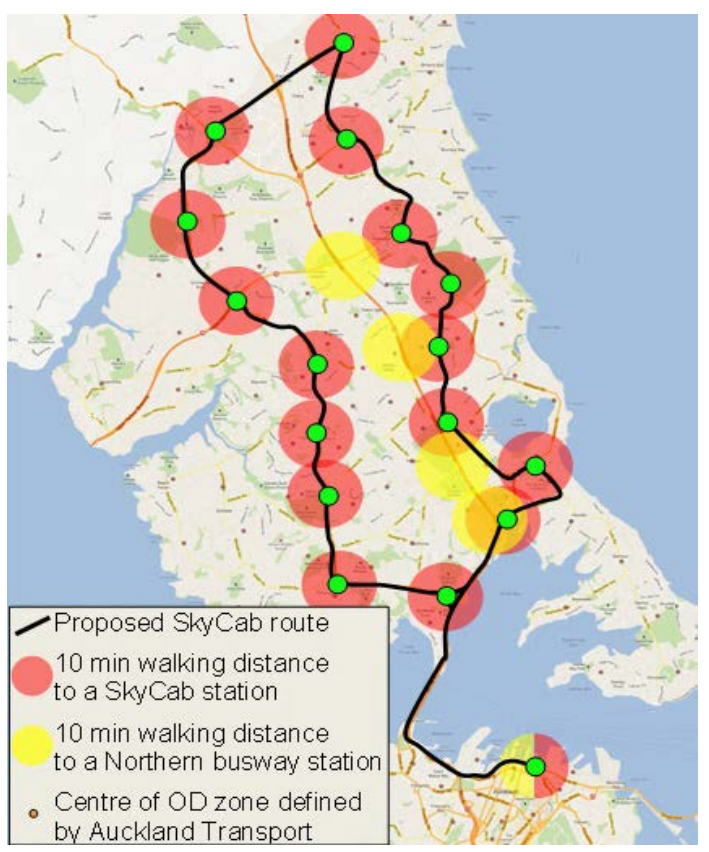

Figure 5. Map of the North Shore showing proposed network and stations.

therefore adjustments were considered not necessary (Ceder, 2006). A relative utility value of 0 was used for the existing bus system compared to a utility value of 0.56 for SkyCabs.

This data of the case study was taken before the implementation of the Northern Busway and as such there is no dedicated high speed bus service on the north shore, leading to a relative utility value of 0 for bus services. The output of the MNL predicts a $60 \%$ mode shift to SkyCabs from other PT services, this is a rough approximation and has only been used as a starting point in the modelling process.

2) Mode switch from private vehicles

Because the data used in the case study is from 2006 it is possible to use the percentage of people new to PT on the Northern Busway so as to give an estimate of the possible mode switch to SkyCabs from private vehicles.

The percentage of Northern Busway users new to PT in 2008 was 39\% (Cleghorn, 2009) and during the AM peak hour the Busway carries the equivalent of 5100 cars (Auckland Regional Council, 2010), which equates to 6630 persons/hour, based on an average vehicle occupancy of 1.3 (Åberg, 1988; Fabian, 2004). The 39\% of 6630 is 2586 trips which is $11 \%$ of the total number of private vehicle trips along the same route in 2006 (from AT supplied data).

This gives an idea on the number of private vehicle trips that could be expected to transfer to a SkyCabs network in an urban area without a dedicated PT service.

Using these mode switch percentages and the station O-D matrices it was possible to obtain final passengers boarding per hour numbers for input into the model.

\subsubsection{The VISSIM Simulation}

The software used to model the network of the case study was PTV VISSIM. The VISSIM simulation is capable of reproducing the exact specifications of the SkyCabs system, but for simplification instead of running on demand as with the real system the cabs are set to originate within the loop at set headways (these headways change as cabs begin to move passengers and stop at different stations). By keeping the headways above the SkyCabs minimum of six seconds the impact of this compromise on the output is minimal. Two different starting headways were used for each demand level simulated; these were 15 and 30 seconds, corresponding to 160 cabs within the network and 300 cabs within the network respectively.

The network itself was modelled as two single lane loops running in opposite directions. The limitation of this is that some of the shorter internetwork trips had to be ignored due to not being able to split a PT route based on demand with the amount of time available. As most trips during the AM peak are to and from the CBD this li- 
mitation only minimally negatively affects the demand on the system and as such the results provided by the simulation should only be improved in practice.

Each direction had its own stop for every station, resulting in the need to calculate a clockwise and an anticlockwise demand for each station, this was done on excel using similar methods to the zone to station reconciliation (i.e., how far is a person willing to travel to board a PT service for a given length trip).

The model required two inputs at every station, the number of passengers boarding per hour and the percentage of passengers in the cab alighting at that stop. The passengers boarding per hour was calculated using the methods presented above. The percentage alighting was calculated by dividing the total number of trips with that station as a destination by the total number of trips within the network.

The simulation runs lasted four hours each, the first hour being the network warm up where cabs were circulated around the network so they would be realistically distributed through the network when demand commenced, for the next two hours demand at each station represented the AM peak and in the final hour demand was reduced and the cabs allowed to drop off any passengers picked up within the two hour peak.

Each cab was modelled as a bus with the custom characteristics of the SkyCabs system applied (capacity, acceleration, speed etc.). The output of the simulation runs are presented in the results section.

\subsection{Economic Analysis Methodology}

The economic analysis comprised of determining all the expected benefits and costs for the following modes of transport in order to determine and compare the final benefit-cost ratios.

- SkyCabs

- Personal Rapid Transit (PRT)

- Light Rail

- Group Rapid Transit (GRT)

The case study was completed by using the hypothetical SkyCab network situated on the North Shore of Auckland shown in Figure 5. This is comprised of a $46.1 \mathrm{~km}$ two-way loop connecting Auckland's North Shore to the Britomart transport center in the CBD. There are 17 stations spread out at approximately $2 \mathrm{~km}$ spacing's. It was decided to use this case study for the following reasons:

- Low population density on the North Shore.

- The only public transport operating in the area are bus services (with minimal ferry services). This poses a unique opportunity to analyse the SkyCab system in an area with poor public transport services.

- The bottleneck at the Harbour Bridge is difficult to overcome for many public transport options.

- The North Shore experiences widespread peak hour congestion.

\subsubsection{Travel Time Cost Savings (TTS)}

The travel time cost savings are the monetary savings due to the decreased travel time for each of the modes of transport analysed when compared to the "do-minimum". The do-minimum used throughout the economic analysis is the existing transport situation on Auckland's North Shore, comprising of buses and private vehicles. Ferry services are ignored, in this research, as they have a minimal influence on the overall public transportation structure. Described below is the methodology used to calculate the travel time cost savings as per the New Zealand's Transport Agency (NZTA) Economic Evaluation Manual (EEM) (NZTA, 2010).

The first step was to determine the expected percentages of people transferring from private vehicles and buses to each of the transport modes analysed. As shown above in Section 3.2.2 the MNL Model and the Northern Busway were used to conservatively determine that $60 \%$ of bus passengers and $11 \%$ of private vehicle users are expected to transfer to SkyCabs. The transfer percentages are largely based on travel time, level of service, average travel speed and accessibility. After undertaking a sensitivity analysis (see Section 4.3.1) it was seen that the economic evaluation is highly sensitive to these transfer percentages, and as a result it was decided to be conservative when estimating transfer percentages in order to not overstate the results. The final estimated transfer percentages are largely based on the relative travel speeds and level of service and are shown in Table $\mathbf{1}$.

These transfer percentages were multiplied by the origin destination data which was converted to average daily traffic by assuming that the two hour morning peak is $10 \%$ of the total daily traffic (NZTA, 2012) to determine the final expected daily patronage matrices for each mode analysed. The base cost of time was determined to be $\$ 16.25 / \mathrm{hr}$ using Table A4.1 (NZTA, 2010) of the EEM (using all occupants and all vehicle types 
Table 1. Estimated transfer percentages.

\begin{tabular}{ccc}
\hline & From Bus & From Private Vehicle \\
\hline To SkyCab & $40 \%$ & $7 \%$ \\
To PRT & $40 \%$ & $7 \%$ \\
To Light Rail & $30 \%$ & $5 \%$ \\
To GRT & $35 \%$ & $6 \%$ \\
\hline
\end{tabular}

and taking an average of urban arterial and urban other type roads). This, along with the average travel speeds (determined in Section 4.1.2), passenger matrices, and the station distance matrix (calculated using Auckland Councils GIS viewer) were used to calculate the travel time costs per annum. The travel time cost savings were then calculated for each mode of transport by subtracting from the do-minimum. The last step was to convert the cost savings to present value using a 30 -year period of analysis and $8 \%$ discount rate.

\subsubsection{Crash Cost Savings (CCS)}

The crash cost savings are the monetary savings due to the decreased number of crashes occurring as a result of people transferring to SkyCabs, PRT, Light Rail or GRT. Described below is the methodology used to calculate the crash cost savings as per NZTA (2010) which is the NZTA's Economic Evaluation Manual (EEM).

The first step was to use the NZTA's Crash Analysis System (CAS) database (NZTA, 2010) to determine the crash history occurring on Auckland's North Shore from 2007 to 2011. As recommended by the EEM, a 5-year period was used as this is the minimum time in which we can obtain reliable crash data.

The factors below, obtained from the EEM of the NZTA manual (NZTA, 2010) were applied to the crash data to calculate the crash costs per annum for the do-minimum.

- Adjust by crash severity (EEM Table A6.19(a))

- Adjust for accident trends (EEM Table A6.1(a))

- Apply under-reporting factors (EEM Tables A6.20(a) and (b))

- Apply accident costs for fatal, serious, minor and non-injury type crashes (EEM Tables A6.21(a)-(h))

- Adjust for mean speed

Once the crash costs were calculated they were then converted to present value using a 30-year period of analysis and $8 \%$ discount rate. Lastly, the total crash costs were multiplied by the estimated transfer percentages shown in Table 1 in order to calculate the expected crash cost savings for each transport mode analysed.

\subsubsection{Vehicle Operating Cost Savings (CCS)}

The vehicle operating cost savings (VOCS) are the monetary savings due to the expected decrease in the number of vehicles on the road as a result of people transferring to SkyCabs, PRT, Light Rail or GRT. The vehicle operating costs can be broken down into two components, the first being a base cost of running the vehicle, and the second being an additional cost due to road surface roughness. Described below is the methodology used to calculate the VOCS as per the EEM (NZTA, 2010).

The first step involved calculating the passenger-km matrices for the do-minimum using the distance matrix and patronage matrices calculated in Section 3.3.1.1. This was calculated separately for both private vehicles and buses as these have significantly different vehicle operating costs. In order to obtain the vehicle operating costs per annum these matrices were multiplied by the base vehicle operating costs and additional costs due to road surface roughness found using Tables A5.1, A5.12 and A5.6 of the EEM. These tables were used assuming an average gradient of $0 \%$, average road roughness (IRI) of $3.0 \mathrm{~m} / \mathrm{km}$ and average bus and vehicle travel speed of $19.3 \mathrm{~km} / \mathrm{hr}$ and $38.7 \mathrm{~km} / \mathrm{hr}$ respectively, as found in the comparative analysis shown in Section 4.1.2. The vehicle operating costs per annum were converted to present value using a 30 -year period of analysis and $8 \%$ discount rate. Lastly, the total vehicle operating costs for the do-minimum were multiplied by each of the transfer percentages shown in Table 1 in order to calculate the final vehicle operating cost savings for each of the transport modes analysed.

\subsubsection{Operation \& Maintenance Cost Savings (O\&M CS)}

The operation and maintenance cost savings (O\&M CS) are the monetary savings expected as a result of imple- 
menting a SkyCab, PRT, Light Rail or GRT type system when compared to the do-minimum. The annual O\&M costs were calculated by multiplying the average O\&M costs determined in Section 4.1.4 by the same passenger-km matrices calculated in Section 3.3.1.3. The O\&M costs for each transport mode were then subtracted from the do-minimum costs in order to find the O\&M cost savings.

\subsubsection{Estimated Tourism Benefits (TB)}

The expected tourism benefits (TB) are the monetary benefits expected to be added to the local economy due to an increased number of tourists visiting the area. It was decided, after liaising with SkyCabs International Ltd, to assume that an extra 10\% of tourists entering through Auckland Airport each year will visit the North Shore and spend an average of $\$ 6.00$ per return trip as a direct result of constructing a SkyCabs network. It was also estimated that an extra $10 \%, 5 \%$ and $7.5 \%$ of tourists will visit the North Shore as a result of a PRT, Light Rail or GRT system being implemented respectively. These expected yearly tourism benefits were then extrapolated to determine the total expected tourism benefits over a 30 -year period of analysis assuming $0 \%$ tourism growth over this time.

\subsubsection{Capital Costs}

The total capital costs are the cost of constructing all the infrastructure, vehicles and operating systems without including the land acquisition costs. It was found upon completion of a sensitivity analysis in Section 4.3.1 that the benefit-cost ratio is highly sensitive to the SkyCabs capital costs. As a result it was decided that the land acquisition costs be ignored in order to be more conservative so as to be careful not to overstate the results. The total capital costs for each of the transport modes analysed were calculated by multiplying the average capital costs determined in Section 4.1.5 by the length of the North Shore loop.

\subsubsection{Benefit-Cost Ratio}

Once all the benefits and costs had been calculated then the final step was to calculate the final benefit-cost ratios (BCR) for each of the transport modes analysed. This was calculated using Equation (2).

$$
\text { BCR }=\frac{\text { Total benefits }(\$)}{\text { Capital Cost }(\$)}
$$

The total benefits include the travel time, crash, vehicle operating, and Operation \& Maintenance (O\&M) cost savings as well as the estimated tourism benefits.

\subsubsection{Sensitivity Analysis Methodology}

A sensitivity analysis was carried out for all the SkyCab variables used in the economic analysis. This was required as the SkyCab system is yet to be constructed in reality and as a result the SkyCab variables used in the analysis are only estimates based on information gathered from independent consultants and manufacturers. The sensitivity analysis was carried out by increasing and decreasing the following SkyCab variables by $10 \%$ and observing the resultant percentage change in benefit-cost ratio using the model created on Microsoft Excel.

- Capital cost

- Average travel speed

- Expected transfer percentages

- Operation and Maintenance costs

- Estimated tourism benefits

From the results of the sensitivity analysis it is determined which variables to be conservative with when performing the economic analysis so as to be careful not to overstate the result.

\section{Results and Discussion}

\subsection{Comparative Analysis}

Sections 4.1.1 to 4.1.5 discuss the results of the comparative analysis as shown below in Table 2.

\subsubsection{Maximum Capacity}

As explained earlier, the capacities shown are the maximum theoretical capacities. This is dependent on the 
Table 2. Results of the comparative analysis.

\begin{tabular}{|c|c|c|c|c|c|c|}
\hline & SkyCab & Bus/Bus lane & Car/Road lane & Light Rail & PRT & GRT \\
\hline Capacity Seated & 4800 pass/hr/dir & 3000 pass/hr/dir & 2160 pass/hr/dir & 3600 pass/hr/dir & 2400 pass/hr/dir & $7200 \mathrm{pass} / \mathrm{hr} / \mathrm{dir}$ \\
\hline $\begin{array}{l}\text { Capacity Including } \\
\text { Standees }\end{array}$ & $9600 \mathrm{pass} / \mathrm{hr} / \mathrm{dir}$ & 4800 pass/hr/dir & 2160 pass/hr/dir & 6000 pass/hr/dir & 2400 pass/hr/dir & $9000 \mathrm{pass} / \mathrm{hr} / \mathrm{dir}$ \\
\hline Average Travel Speed & $60 \mathrm{~km} / \mathrm{hr}$ & $19.3 \mathrm{~km} / \mathrm{hr}$ & $38.7 \mathrm{~km} / \mathrm{hr}$ & $43 \mathrm{~km} / \mathrm{hr}$ & $39 \mathrm{~km} / \mathrm{hr}$ & $30 \mathrm{~km} / \mathrm{hr}$ \\
\hline Energy Consumption & $0.7 \mathrm{MJ} /$ pass-km & 3.15 MJ/pass-km & $2.38 \mathrm{MJ} /$ pass-km & $2.08 \mathrm{MJ} /$ pass-km & $0.55 \mathrm{MJ} /$ pass-km & 2.16 MJ/pass-km \\
\hline Capital Cost (NZ\$/km) & $\$ 13,000,000$ & $\$ 53,500,000$ & $\$ 47,000,000$ & $\$ 40,000,000$ & $\$ 14,800,000$ & $\$ 44,600,000$ \\
\hline $\begin{array}{c}\text { O\&M Costs } \\
\text { (NZ\$/pass-km) }\end{array}$ & $\$ 0.33$ & $\$ 0.63$ & $\$ 0.29$ & $\$ 0.48$ & $\$ 0.35$ & $\$ 0.39$ \\
\hline
\end{tabular}

minimum practicable headway and maximum vehicle occupancy. As seen in Table 2, SkyCabs has the largest maximum theoretical capacity (when including standees) of 9600 passengers/hour/direction which is similar to that of a 4 lane motorway (Chapman et al., 2011). This is due to the low headways (minimum of 6 seconds) and high vehicle occupancy (maximum of 16 passengers) when compared to the other modes of transport analysed. Cars and PRT can achieve headways less than 3 seconds; however they are compromised by their low vehicle occupancies. Conversely, GRT, Light Rail and buses have high vehicle occupancies however they are limited by their much lower headways.

\subsubsection{Average Travel Speed}

The average travel speeds shown are the speeds including all stoppages and delays. They are dependent on the line speed, number of stops, distance between stops, the dwell time and the length of the trip. As seen in Table 2, SkyCabs has the fastest average travel speed of $60 \mathrm{~km} / \mathrm{hr}$. This is due to being able to achieve high line speeds (maximum of $80 \mathrm{~km} / \mathrm{hr}$ ) with minimal stops along the way. PRT requires no intermediate stops, however its average speed is relatively low as it is restricted by its low line speeds as a result of the small cabs. Bus and Cars can achieve high line speeds, up to $100 \mathrm{~km} / \mathrm{hr}$ on some stretches of road; however they are heavily affected by traffic signals, intersections and congestion resulting in queuing and low average speeds. GRT and Light Rail also have high line speeds, however they are required to stop often to pick up and drop off passengers along the route. This has the effect of dramatically reducing their average speeds.

\subsubsection{Energy Consumption}

All energy consumption values shown in Table 2 come from 'Personal Rapid Transit for Airport Applications' (Lowson, 2005), except SkyCabs which comes from 'A New Architectural Design of Elevated Small Group Automated Rapid Transit' (Chapman et al., 2011). It is seen that SkyCabs and PRT have similar energy use values of $0.70 \mathrm{MJ} /$ pass-km and $0.55 \mathrm{MJ} /$ pass-km respectively. These are significantly lower than the energy consumed by bus, cars, light rail and GRT.

This is primarily due to their similar system characteristics and operating systems. These comprise of lightweight, electric cabs which are significantly more energy efficient than that of petrol and diesel engines used in most cars and buses.

\subsubsection{Operation and Maintenance (O\&M) Costs}

All O\&M costs shown in Table 2 are derived from "Viability of Personal Rapid Transit in New Jersey" (Carnegie et al., 2007), except SkyCabs which are directly from SkyCabs International Ltd. These costs are largely dependent on the level of service, efficiency, scale, selected technology and management practices of each system (Carnegie et al., 2007). As seen in Table 2, there is no significant difference between SkyCabs, Light rail, cars, PRTs or GRTs operation and maintenance costs. These all lay within the range of $\$ 0.29-\$ 0.48$ per passenger-km. However, bus systems have significantly larger operation and maintenance costs due to the higher staffing costs brought about as a result of higher operator to vehicle capacity ratios. SkyCabs and PRTs operation and maintenance costs are low due to high levels of automation, reducing staffing needs as well as the use of on-demand service reducing energy use and vehicle wear. 


\subsubsection{Capital Costs}

The capital costs shown in Table 2 include the costs of the infrastructure, cabs and operating systems. These costs can vary significantly depending on location and topography, as well as other factors such as the extent of bridging and tunnelling required. To counteract this variability and to make the comparison more viable it was decided to use case studies located in Auckland when determining capital costs. Where this was not possible, overseas case studies with similar properties to that on the North Shore were used. Listed below are the already built and proposed case studies used to determine the capital costs for each mode of transport analysed.

- The SkyCab capital costs were determined upon consultation with SkyCabs International Ltd.

- The Northern Busway completed on Auckland's North Shore in 2008 was used to determine the capital cost of a two-way dedicated bus lane.

- The proposed 'holiday highway' from Puhoi to Wellsford in Auckland was used to determine the capital cost of a two way road.

- The light rail capital costs were determined using the Light Rail system located in Charlotte, North Carolina, USA. This was chosen as it was predominantly built at-grade with the exception of two overpasses. This is what would be expected if a light rail system were to be built on the North Shore of Auckland.

- PRT costs were determined from the ULTra system constructed at Heathrow airport. These costs are per kilometer of one-way track and are therefore used conservatively.

- GRT capital costs are from the Morgantown GRT system located in Morgantown, West Virginia, USA.

As seen in Table 2, the SkyCab system has the lowest average capital costs when compared to the other transport modes analysed. This is largely due to the lightweight nature of the cabs which results in low live loads and hence minimal infrastructure and support systems being required.

\subsection{Operational Analysis}

\subsubsection{Level of Service and Model}

Figure 6 shows that the number of trips within easy walking distance of a PT station is three times higher for SkyCabs than the Northern Busway. This is a great indicator of the accessibility of the service and is an important result because improving accessibility to public transport services is vital to providing a high quality sustainable travel (Hawkes, 2008).

The five simulation runs shown in Table 3 represent varied demand levels based on the mode switch percentages obtained. Case 5 represents the case of the full demand on the Northern Busway being carried by the SkyCabs network.

Figure 7 shows that the dwell time of the SkyCabs is consistent over a wide range of demand levels. And Figure 8 shows that highest dwell time of a SkyCab is still much lower than the average dwell time of a bus (NZTA, 2010; Sullivan \& O’Fallon, 2003). Low and consistent dwell times are important because the perceived stop time is much greater than actual stop time (Ceder, 2007) and minimising these delays adds to an individual traveler's sense of this being a personal trip.

The waiting time is one of the most important factors when it comes to the level of service offered by a public transport service. Both a low and consistent waiting time are key factors (Ceder, 2007), passengers need to know

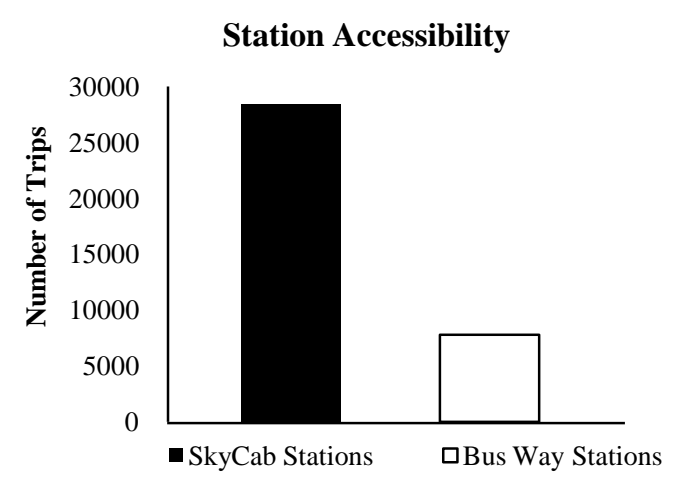

Figure 6. Number of trips within a 10 min walking distance of a dedicated PT station. 
Table 3. Demand levels based on various percentage switches from other trip modes.

\begin{tabular}{ccc}
\hline Case \# & Demand (pass/hr) & Modal Transfers \\
\hline 1 & 2825 & $40 \%$ PT 7\% PV \\
2 & 3435 & $60 \%$ PT 7\% PV \\
3 & 3575 & $60 \%$ PT 11\% PV to CBD 7\% PV Other \\
4 & 3563 & $60 \%$ PT 5\% PV to CBD 7\% PV Other \\
5 & 5279 & $60 \%$ PT 100\% PV to CBD \\
\hline
\end{tabular}

Where, $\mathrm{PT}=$ public transport and $\mathrm{PV}=$ private vehicles.

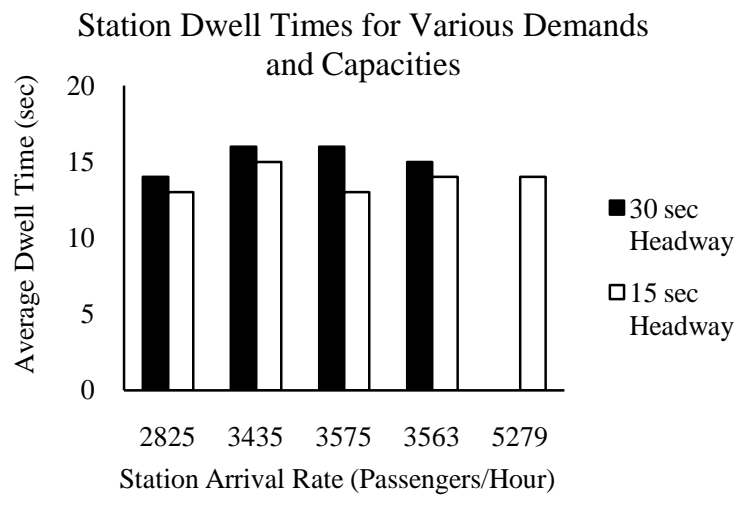

Figure 7. SkyCab dwell times for various demand levels.

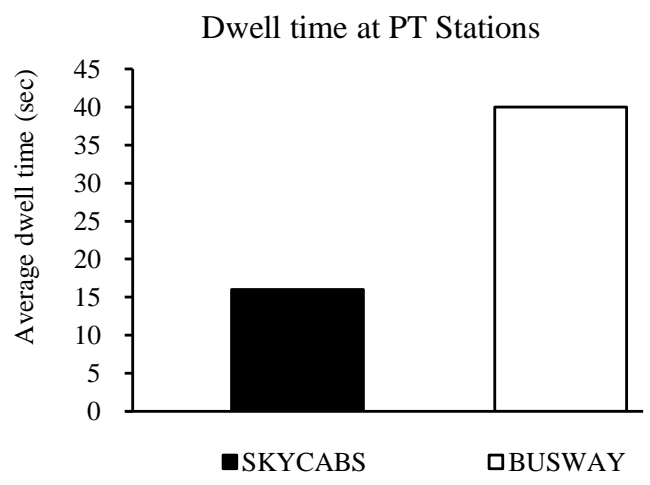

Figure 8. SkyCab vs. Bus dwell times.

that they can leave their house at the same time every day and not have to worry about being late for work because they had to wait twice as long as the day before.

Figure 9 shows good consistency among the wait times for a varied demand which is good for passengers as the demand level may have minor fluctuations from day to day; this result shows that these minor fluctuations will not negatively impact their journey planning.

Figure 10 shows that the average wait time for a SkyCab at the highest demand on the network is much less than the average wait time on the Northern Busway. The wait time for the Northern Busway is calculated by dividing the headway by two. The headway during busy periods is 3 minutes (Maxx-Auckland Transport, 2012). Again, this is important as the perceived wait time is greater than the actual wait time, so even a small reduction can greatly affect the level of service offered to passengers (Ceder, 2007).

It was noticed that the wait time increased, as expected, between Cases 1 and 2 when the demand increased; however, the wait time for case three was reduced even though the demand was higher. The theory behind this is that that Case 3 has lower wait time than Cases 1 and 2 due to the higher proportion of trips to the CBD; it is 


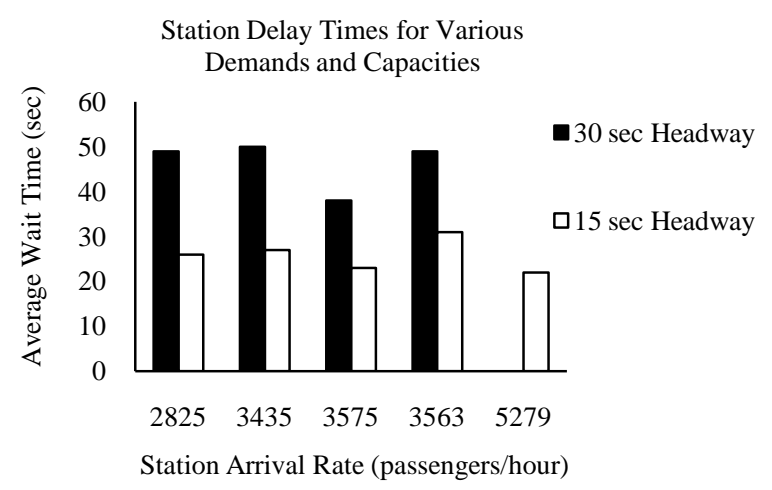

Figure 9. SkyCab wait times for various demand levels.

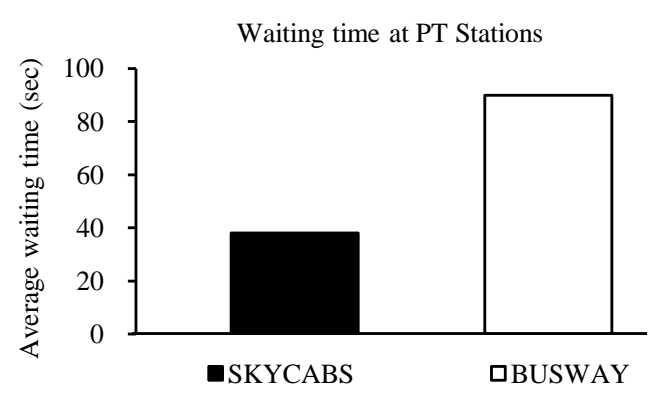

Figure 10. SkyCabs vs. Northern Busway wait times.

theorised that more people are getting into the cabs to go to the same destination from the same origin (many of the trips into the CBD originate close together) and in doing so lessen the average wait time across the network. The higher occupancy per cab unfortunately does not show up significantly in the average occupancy rates due to the minimal increase in demand, but the average occupancy for Case 3 is higher than for Case 2.

This theory is supported by the results of Case 4 where the overall demand was kept roughly the same, but the proportions where changed; thus more of the trips were inter-network trips. Figure 9 clearly shows that the average wait time increases back to the levels expected based on the results from Cases 1 and 2.

Case 5 was run as a test of the SkyCabs capability to operate as a collector network feeding the CBD, as is the current function of the Northern Busway. The demand was set to roughly equal to the current demand on the Busway and the proportions were weighted in such a way that most of the trips were to the CBD (as is the case with the Busway). The results show the lowest waiting time yet which again supports the theory that the modelled network is extremely efficient at moving large amounts of people into the CBD.

Figure 11 shows that cab occupancy is fairly consistent across minor changes in demand. Ideally no passengers should have to stand to offer the level of service aspired to by SkyCabs, for this reason it can be seen that for demands consistently over 2900 passengers per hour the number of cabs in the network would need to increase. For demands in the range of 2900 to 5280 passengers per hour it can be seen that an approximate initial headway of $15 \mathrm{sec}$ would be appropriate, which corresponds to roughly 150 cabs in each loop of the network. This number is somewhat inflated due to limitations of the model and how the cabs choose where to go and where to stop.

\subsection{Economic analysis results and discussion}

Figure 12 and Table 4 contain the results of the economic analysis.

The travel time cost savings (TTS) are dependent on the average travel speed found in the comparative analysis (refer to Section 4.1.2) and the expected transfer percentages from buses and private vehicles (refer to Table 1). As was already mentioned, the cost savings due to waiting time have not been included due to lack of reliable data. As seen in Figure 12, SkyCabs has significantly larger travel time cost savings than all other transport modes analysed due to its fastest average travel speed and high estimated transfer percentages. 


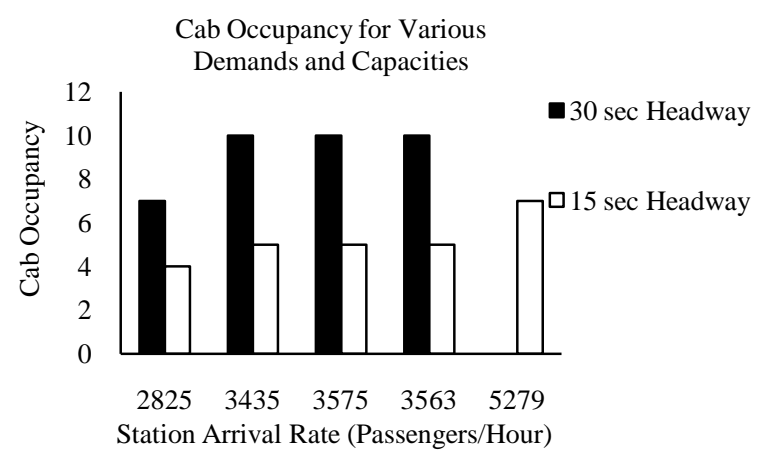

Figure 11. Cab occupancy rates for various demand levels.

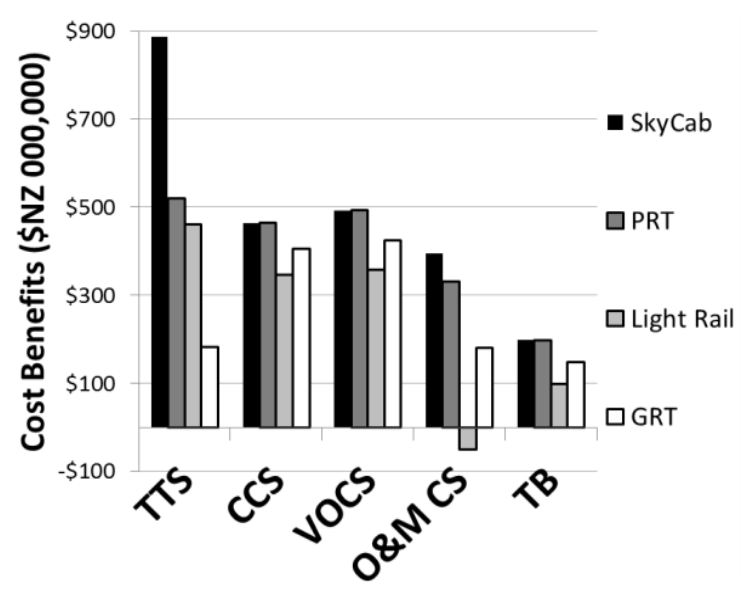

Figure 12. Cost benefits for the transport modes analysed.

Table 4. Resultant benefit cost ratio table.

\begin{tabular}{ccccc}
\hline & SkyCab & PRT & Light Rail & GRT \\
\hline Total Benefits (NZ\$000,000) & $\$ 2436$ & $\$ 2005$ & $\$ 1212$ & $\$ 1342$ \\
Capital Cost (NZ\$000,000) & $\$ 617$ & $\$ 682$ & $\$ 1844$ & $\$ 2056$ \\
Benefit Cost Ratio & 3.94 & 2.94 & 0.66 & 0.65 \\
\hline
\end{tabular}

The CCS and VOCS for SkyCabs, PRT, Light Rail and GRT are wholly dependent on the estimated transfer percentages. As seen in Figure 12, SkyCabs and PRT have the largest crash and vehicle operating cost savings due to having the highest estimated transfer percentages.

The O\&M CS are dependent on the transfer percentages and the average O\&M costs determined in the comparative analysis (refer to Section 4.1.4). From Figure 12 it is apparent that SkyCabs has the largest O\&M cost savings due to having the lowest average O\&M costs and largest expected transfer percentage. Light rail has a negative O\&M cost saving as its average O\&M costs are larger than that of the do-minimum.

Lastly, the estimated TB were calculated based on the estimated increase in the number of tourists visiting the North Shore as a direct result of either a SkyCab, PRT, Light Rail or GRT system being built. As explained earlier, it was conservatively estimated that an extra $10 \%$ of tourists travelling through Auckland will visit the North Shore in order to travel on the SkyCab system. This is due to the elevated cabs and fast average speed providing a quick and convenient way for tourists to view the entire North Shore. In addition to this, the construction of a new, innovative form of public transport, such as SkyCabs, would likely be featured in most tourism guides on Auckland which will result in a larger number of tourists visiting the area.

Finally, as seen in Table 4, SkyCabs has the largest benefit-cost ratio with a value of 3.94, significantly larger than that of PRT, Light Rail and GRT. This shows that implementing a SkyCab system into Auckland’s North 
Shore is economically viable, with the expected monetary benefits outweighing the expected capital costs by almost four to one. It is not economically viable if the benefit-cost ratio is less than one, as seen in the case of Light Rail and GRT.

\subsection{Sensitivity Analysis Results and Discussion}

Figure 13 provides the results of the sensitivity analysis.

The most sensitive variables are shown on the left of the graph of Figure 9, whereas the least sensitive variables are shown on the right. It is seen that the capital cost and transfer percentages are the most sensitive SkyCab variables used in the economic analysis. Thus it was decided to be conservative and careful, when using these values, so as not to overstate the results. It was found that the O\&M costs, average travel speed and expected tourism benefits are not as sensitive and were therefore not used as conservatively.

\section{Conclusion}

This work describes the SkyCabs concept comprised of many, lightweight, driverless cabs running two ways on a single elevated monobeam. With each cab seating up to eight people, the aim is to create a feeling of personal travel, and in doing so increase the level of patronage on public transport services. The work investigates the SkyCabs system based on the following three criteria; a comparative analysis which involves researching and comparing system characteristics, a computer simulation analysing operational feasibility and an economic analysis which involves calculating and comparing the benefit-cost ratios for each mode analysed. The results obtained through the modelling and simulation clearly shows that SkyCabs has significantly lower dwell and wait times than that of buses. Furthermore, it was also seen that the expected cab occupancy is lower than its capacity for every demand level tested. The comparative analysis shows that, overall, SkyCabs has favourable system characteristics when compared to all other modes of transport analysed. The economic analysis shows that SkyCabs is the most economically viable option when compared to PRT, light rail and GRT. It is therefore concluded that the implementation of a SkyCabs system into any urban environment with similar characteristics

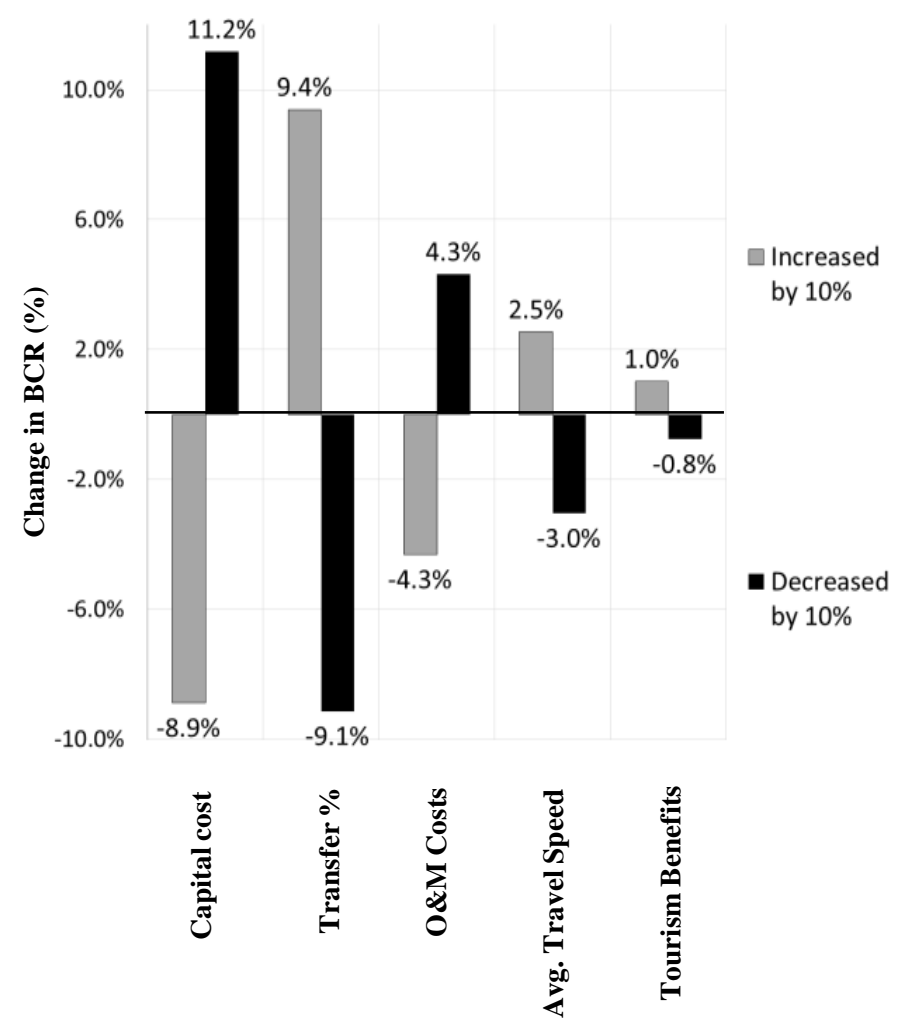

Figure 13. Results of the sensitivity analysis. 
to that of Auckland's North Shore is feasible. It is recommended that transport decision makers carefully consider SkyCabs as a viable alternative to other traditional and modern modes of public transport.

\section{Acknowledgements}

The authors are very grateful to Hugh and Mary Chapman, founders of SkyCabs International Ltd, for their collaboration, information provision and encouragement of this work.

\section{References}

Åberg, L. (1988). Driver Behavior at Flashing-Light, Rail-Highway Crossings. Accident Analysis and Prevention, 20 , 59-65. http://dx.doi.org/10.1016/0001-4575(88)90015-2

Auckland Regional Council (2010). Like a Railway, but with Buses. Region Wide-News and views from the Auckland Regional Council.

Auckland Regional Transport (2010). Auckland Regional Land Transport Strategy, 2010-2040 [Electronic Resource]. Auckland, NZ: Auckland Regional Council.

Bachels, M., Newman, P. D., \& Kenworthy, J. R. (1999). Indicators of Urban Transport Efficiency in New Zealand's Main Cities: An International City Comparison of Transport, Land Use and Economic Indicators. Murdoch, WA: Institute for Science and Technology Policy, Murdoch University.

Carnegie, J. A., Voorhees, A. M., \& Hoffman, P. S. (2007). Viability of Personal Rapid Transit in New Jersey. Presented to Governor Jon S. Corzine and The New Jersey State Legislature: Department of Transportation, The State of New Jersey.

Ceder, A. (2006). Planning and Policy of Ferry Passenger Service in Hong Kong. Transportation, 33, 133-152. http://dx.doi.org/10.1007/s11116-005-3047-1

Ceder, A. (2007). Public Transit Planning and Operation: Theory, Modelling and Practice. London: Elsevier.

Chapman, H. (2006). SkyCabs Your Destination, Our Goal. http://www.skycabs.co.nz/Product.htm?4

Chapman, H., Chapman, M., \& Ceder, A. (2011). A New Architectural Design of Elevated Small Group Automated Rapid Transit. Journal of Public Transportation, 14, 63-87.

Cleghorn, D. (2009). Improving Pedestrian and Motorist Safety along Light Rail Alignments. TCRP Report 137, Washington DC: Transportation Research Board.

Coleman, A. (2010). Transport Infrastructure, Lock-Out, and Urban Form: Highway Development in Auckland and the United States. In RESEARCH, M. E. A. P. P. (Ed.).

Davidson, S. (2004). Ultra-Light Rail is Moving Right along. (Progress) (Bishop Austrans Mass Transit Rail system). Ecos, 13.

Dawson, P. E. (2003). SkyCabs: An Analysis of an Alternative Transport Proposal for the Auckland Region. Research Study (BPlan)-University of Auckland.

Fabian, L. (2004). The Safety Record of Automated Guideway Transit. A Planners Guide to Automated People Movers. Trans. 21, Transportation Systems of the Twenty-First Century. Boston.

Grimes, A. (2007). Transformative Transport: Transport and Economic Transformation. In Transport-The Next 50 Years Conference. Christchurch.

Harris, C. E. (2005). Slow Train Coming: The New Zealand State Changes Its Mind about Auckland Transit, 1946-56. Urban Policy and Research, 23, 37-55. http://dx.doi.org/10.1080/0811114052000341946

Haub, C. (2008). 2008 World Population Data Sheet. 2008 Population Reference Bureau.

Hawkes, G. (2008). Dedicated Busway a Roaring Success. LG Mediawebnz.

Hensher, D. A. (2007). Bus Transport: Economics, Policy and Planning. Research in Transportation Economics, 18, xix, 1-xxviii, 507. http://dx.doi.org/10.1016/S0739-8859(06)18001-4

Jakob, A., Craig, J. L., \& Fisher, G. (2006). Transport Cost Analysis: A Case Study of the Total Costs of Private and Public Transport in Auckland. Environmental Science and Policy, 9, 55-66. http://dx.doi.org/10.1016/j.envsci.2005.09.001

Kerr, A. D., James, P. A., \& Craig, A. P. (2005). Infrastructure Cost Comparisons for PRT and APM. ASCE APM05 Special Sessions on PRT.

Laird, P. G., Newman, P., Bachels, M., \& Kenworthy, J. (2001). Back on Track: Rethinking Transport Policy in Australia and New Zealand. Sydney: UNSW Press.

Lee, M. (2011). The Fall and Rise of Public Transport in Auckland (Part 1). YouTube. 
http://www.youtube.com/watch?v=J2q4apeo_kE

Lowson, M. (2005). Personal Rapid Transit for Airport Applications. Transportation Research Record: Journal of the Transportation Research Board, 1930, 99-106. http://dx.doi.org/10.3141/1930-12

Maxx-Auckland Transport. (2012). www.maxx.co.nz

Monorails.org (2012). www.monorails.org

Muller, P. J. (2007). A Personal Rapid Transit/Airport Automated People Mover Comparison. In Varma, A. (Ed.), Aviation: A World of Growth. The 29th International Air Transport Conference. Irving Texas: American Society of Civil Engineers.

Niches (2010). Guidelines for Implementers of Group Rapid Transit (GRT).

NZTA (2010). Economic Evaluation Manual. New Zealand Transport Agency.

NZTA (2012). State Highway Traffic Data Booklet. New Zealand Transport Agency.

Quigley, J. M. (1988). Urban Diversity and Economic Growth (Urban Agglomeration). Journal of Economic Perspectives, 12, 127. http://dx.doi.org/10.1257/jep.12.2.127

Sulkin, M. A. (1999). Personal Rapid Transit Déjà Vu. Transportation Research Record, 1677, 58-63. http://dx.doi.org/10.3141/1677-07

Sullivan, C., \& O’Fallon, C. (2003). Vehicle Occupancy in New Zealand's Three Largest Urban Areas. In 26th Australasian Transport Research Forum. Wellington.

Tassi, P., Saremi, M., Schimchowitsch, S., Eschenlauer, A., Rohmer, O., \& Muzet, A. (2010). Cardiovascular Responses to Railway Noise during Sleep in Young and Middle-Aged Adults. European Journal of Applied Physiology, 108, 671-680. http://dx.doi.org/10.1007/s00421-009-1270-8

Thompson, D. J. (2009). Railway Noise and Vibration [Electronic Resource]: Mechanisms, Modelling and Means of Control. Amsterdam, Boston: Elsevier.

Willmott, D. B. (1998). Urban Traffic “Problems" and the Prospects for Public Transport in Auckland. Wellington, NZ: Institution of Professional Engineers New Zealand.

Wright, C., \& Egan, J. (2000). De-Marketing the Car. Transport Policy, 7, 287-294.

http://dx.doi.org/10.1016/S0967-070X(00)00029-9 